\title{
Effect of Interaction between Traits of Different Genotype Maize in Six Fertilizer Level by GGE Biplot Analysis in Hungary
}

\author{
Seyed Mohammad Nasir Mousavi*, Károly Kith, János Nagy
}

\begin{abstract}
Hungary was one of the main countries in the world as regards the yields reached in maize production. The research was conducted to appraise the effect of NPK fertilizer on traits of different hybrid maize (Fao410, Fao340) at the University of Debrecen and our experiment was carried out in Centre for Agricultural Sciences, Institute of Crop Sciences at Látókép in 2018. NPK fertilizer was applied in six different combinations (0-0-0 control, 30-23-27 first dose, 60-46-54 second dose, 90-69-81 third dose, 120-92-108 fourth dose and 150-115-135 fifth dose $\left.\mathrm{kg} \cdot \mathrm{ha}^{-1}\right)$. The result of compound variance showed the level of fertilizer and interaction between fertilizer and genotypes were significant in one percent. Effect of genotypes was a variable level of fertilizer and providing a different yield in the level of fertilizer. The weight of seeds in ear and weight of ear were important traits in the average yield on Fao410 hybrid. Also, the fourth of the fertilizer level was the best level of fertilizer for yield on Fao410 and Fao340. the weight of fresh plant and weight of seeds in ear were highest relation with yield in $\mathrm{H} 340$ hybrid. The results of this research can successfully contribute to the science of maize cultivars, the given adapted hybrid to the discovery of their traits and to an application of fertilizers.
\end{abstract}

Keywords: maize, NPK fertilizer, GGE biplot

\section{Introduction}

The amount of global annual maize production was 483 million tonnes in 1990 and increased to 705 million tonnes in 2004 . The increment of $67 \%$ in the most dynamic among cereals. Its role in human nutrition and its widespread cultivation have made it the most important crop (Nagy, 2006). Earlier, Hun-

*Corresponding author. E-mail address: nasir@agr.unideb.hu

Department of Land Use and Rural Development, Faculty of Agricultural Sciences, Centre for Agricultural Sciences, University of Debrecen, 4032 Debrecen, Böszörményi út 138, Hungary 
gary was one of the main countries in the world maize production, however, changes in climatic conditions have unfavourable effect on yield of maize (Nagy, 2008).

In 2050, a population of more than 9 billion will depend on the accessibility of plant nutrients in proportion to the necessary increase in productivity, establishment of new crops and technologies, and the cultivation of marginal lands. During the 20th century, production of food enhanced substantially, because of the development of yield. If we take the mean of crop yields from 1900 and from 2000, it is clear that it would need nearly four times more land to catch crop at the 2000 level (Smil, 2011a). Large amounts of nutrients from plants (mainly nitrogen, phosphorus and potash) being removed from the soil at harvesting crops, fertilizers are important in refilling nutrient reserves into the soil. Many authors assert that increasing yield from $30 \%$ to $50 \%$ is due to fertilizers (Heisey and Norton, 2007).

Agriculture is more dependent on arranged utilization of plant nutrients while increasing food production. Hence, you can understand necessary nutrients have risk in food production in the future and will be immensely important in upcoming years. Food and Food Organization forecasts reveal that feeding the global population of 9.1 billion in 2050, over the years 2005/07 to 2050, requires a total incensement of food production by $70 \%$ (FAO, 2009). New forecasts show that rising global demand for food in the year 2050 will have risen by 100 to 110 percent since 2005 (Tilman et al., 2011). From 2005 to 2050 , fertilizer production should be from $50 \%$ to $100 \%$ increasing significantly because of increasing food production and crops. Crop production is cereal oriented in Hungary. So, there is planting area for cereals and small grain and maize around 70\% of total agricultural land between 2.7-2.8 million hectares. The using of fertilizers, nitrogen and other macro elements, $\mathrm{P}$ and $\mathrm{K}$, are parameters of increasing performance to crops (mainly cereals), but using overdose fertilizer caused damage to environment and caused problems to the soil and decrease of quality water and increase of $\mathrm{NO}_{3}-\mathrm{N}$ and caused emissions of greenhouse gases in soil (Li et al., 2007; Van Groenigen et al., 2010). The over NPK fertilizer has huge program for future agriculture because of variable meteorological and soil factors (Ladha et al., 2005; Devkota et al., 2013).

There are increasing yields of maize due to timing, dosing, harmonizing and splitting of N-fertilization with PK fertilizer doses in Hungary (Pepó et al., 2006). However, there is not an acceptable result increasing the fertilizer caused yield of maize (Liu et al., 2003; Pepó et al., 2008) and it might even cause reduction in yield (Lü et al., 2011). Thus, the correct management of nitrogen fertilizer is important and essential in order to keep the high yield of maize and $\mathrm{N}$ efficiency. There are only a few articles about the nitrogen use efficiency (NUE) on the different hybrids of maize (Balko and Russell, 1980; Muruli and Paulsen, 1981; 1982; Akintoye et al., 1999). In general, there is any 
report about $\mathrm{N}$ uptake efficiency to be less than $40 \%$ globally (Raun et al., 2002). Denitrification, soil erosion, leaching and volatilization are correlating with the efficiency of $\mathrm{N}$ on low recovery (Fageria and Baligar, 2005). Effect of the nitrogen depends $24-48 \%$ on nitrogen fertilizer forms (Abbasi et al., 2013). In cereals, nitrogen use efficiency reported ranged from $28 \%$ to $41 \%$ (Zhu and Wen, 1992). Other researchers reported that the NPK fertilizers resulted in more yield than other fertilizers with similar nitrogen content. This result shows that potassium is an important factor for increasing of yield (Duan et al., 2014). Phosphorus is a very important parameter for efficiency fertilizers and nitrogen fertilizers. Thus, phosphorus use efficiency is a big concern for farmers (Schröder et al., 2011). Results of research in China showed that phosphorus use efficiency averaged 13.01 (3.0\% to $49.3 \%$ ) on 165 fields of cereals (Li et al., 1998; Zhu and Wen, 1992).

The purpose of this study was to evaluate the interaction between traits of tow hybrids maize in the different levels of fertilizer in Hungary by GGE biplot.

\section{Method and materials}

In this study, the experimental farm was located at the University of Debrecen and our experiment was carried out in the Centre for Agricultural Sciences, Institute of Crop Sciences at Látókép. The site is located in Eastern Hungary, $15 \mathrm{~km}$ from Debrecen in the Hajdúság Loess region, where the soil is calcareous chernozem ( $\left.\mathrm{N} 47^{\circ} 33^{\prime}, \mathrm{E} 21^{\circ} 27^{\prime}\right)$. The experimental soil was well culture-state, medium-hard loam. Its humus content is medium, $2.8 \%$, its $\mathrm{pH}$ value is almost neutral, $\mathrm{pH}_{\mathrm{KCl}}=6.2$. The soil has proper water management characteristics. The hybrids studied in the experiment were H340(FAO 340 ) and H410(FAO 410). The hybrids were sown with a seed number of 72,000 plants/ha. We applied six fertilization treatments (Table 1). Nitrogen was applied in the form of $34 \%$ ammonium-nitrate (50\% in the spring), the nitrogen $50 \%$ and the phosphorus and potassium fertilizers were solicited in full dosage $(100 \%)$ in the autumn as a 10:15:18 special complex fertilizer.

Table 1. Fertilizer used of long-term experiment (Debrecen, chernozem soil)

\begin{tabular}{|l|r|r|r|r|}
\hline Treatment & $\mathrm{N}$ & $\mathrm{P}_{2} \mathrm{O}_{5}$ & $\mathrm{~K}_{2} \mathrm{O}$ & Total \\
\hline 0 (Control) & 0 & 0 & 0 & 0 \\
\hline 1 & 30 & 23 & 27 & 80 \\
\hline 2 & 60 & 46 & 54 & 160 \\
\hline 3 & 90 & 69 & 81 & 240 \\
\hline 4 & 120 & 92 & 108 & 320 \\
\hline 5 & 150 & 115 & 135 & 400 \\
\hline
\end{tabular}


Table 2. Precipitation and average weather index of this research

\begin{tabular}{|l|c|c|c|}
\hline Month & Precipitation & Temperature & Radiation \\
\hline April (after 24th) & 6.1 & 18.04 & 22.09 \\
\hline May & 57.4 & 19.73 & 23.24 \\
\hline Jun & 63.6 & 20.24 & 21.16 \\
\hline July & 54.6 & 21.66 & 22.53 \\
\hline August & 92.2 & 23.17 & 20.51 \\
\hline September & 13.6 & 17.13 & 15.41 \\
\hline October (until harvest time) & 2.0 & 12.25 & 10.53 \\
\hline
\end{tabular}
ble 2).

The amount of rainfall was $291 \mathrm{~mm}$ after sowing until harvest time ( $\mathrm{Ta}$ -

\section{Result}

\section{Simple and compound variance analysis}

According to a simple variance, there are traits between plant height, ear weight, cob ear weight, the weight of the seeds in ear significance in 5 percent in $\mathrm{H} 340$ also, the weight of fresh plant in 1 percent. This study states that traits were variable in different level fertilizers (Table 3). Also, simple variance showed that there was significance at one percent between traits weight of ear, the weight of cob ear, weight of the seeds in the ear, and weight of the fresh plant in hectare in H410. The study also revealed that traits were variable in different level fertilizers (Table 4). The compound variance showed a level of fertilizer and interaction between fertilizer and genotypes were significant at one percent. Effect of genotypes was a variable different level of fertilizer and we have a different yield in the level of fertilizer (Table 5).

Bencze et al. showed that, based on analysis of variance, the difference in yield of both years were formed only for $\mathrm{N}$ levels. The growth of $\mathrm{P}$ and $K$ levels were significant only in one year and its effects have been growing trendy. The role of phosphorus and potassium in corn grains is reduced and most of them affect the physiological process of corn. Effect on yield was less because it was based on different interactions (Bencze et al., 2017).

\section{Classification of traits by factor analysis and cluster}

We obtained important factors in yield by main factor analysis. This analysis showed that 4 main factors justified approximately $72 \%$ of all data. According to the analysis, first factor was related to traits ear, such as the weight of ear, weight of seeds in ear and number of seeds in an ear that all traits men- 

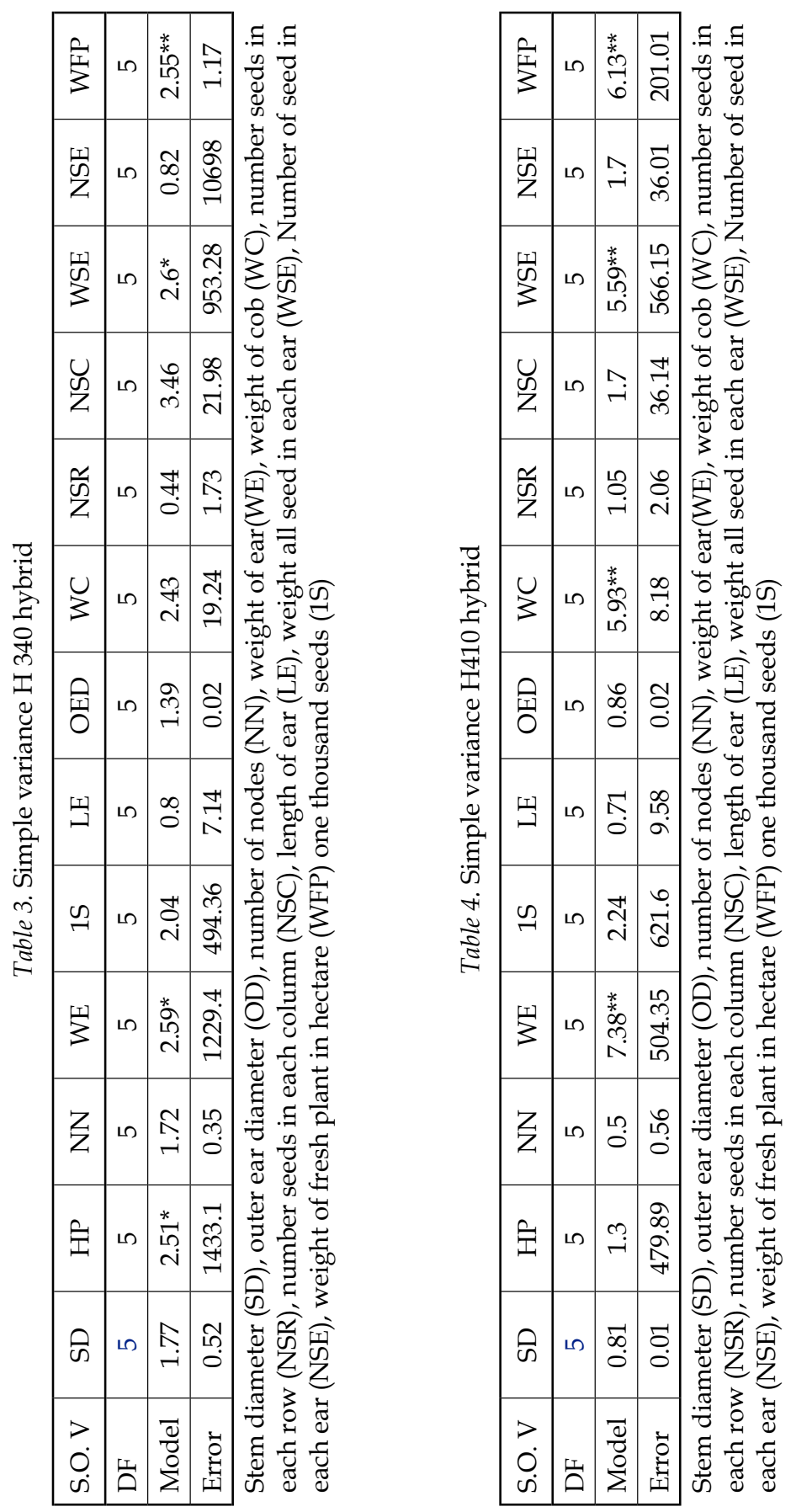
Table 5. Compound variance $\mathrm{H} 410$ and $\mathrm{H} 340$

\begin{tabular}{|l|r|c|c|}
\hline S.O. V & DF & MS & F value \\
\hline Genotype & 1 & 0.98041 & 0 \\
\hline NPK & 5 & 5826.98 & $6.5^{* *}$ \\
\hline Genotype*NPK & 5 & 3246.57 & $3.62^{* *}$ \\
\hline Error & 36 & 895.888 & \\
\hline Total & 47 & & \\
\hline
\end{tabular}

Table 6. Factor analysis in Fao410 and Fao340 hybrids

\begin{tabular}{|l|c|c|c|c|}
\hline Variable & Factor1 & Factor2 & Factor3 & Factor4 \\
\hline Stem diameter & 0.481 & -0.352 & 0.050 & -0.346 \\
\hline Outer ear diameter (CM) & 0.308 & -0.138 & 0.664 & 0.386 \\
\hline Number of nodes (PCS) & 0.206 & 0.315 & 0.347 & -0.290 \\
\hline Weight of ear & 0.870 & 0.398 & -0.237 & 0.041 \\
\hline Weight of COB & 0.828 & 0.376 & -0.311 & 0.022 \\
\hline Number seeds in each row & 0.228 & -0.228 & 0.109 & 0.836 \\
\hline Number seeds in each column & 0.523 & -0.203 & 0.480 & -0.299 \\
\hline Length of ear & 0.259 & -0.191 & 0.530 & -0.388 \\
\hline Weight all seed in each ear & 0.861 & 0.420 & -0.223 & -0.008 \\
\hline Number of seeds in each ear & 0.632 & -0.266 & 0.494 & 0.195 \\
\hline 1000 seeds & 0.555 & 0.084 & -0.169 & 0.080 \\
\hline Weight of plant wet in hectare & 0.340 & -0.811 & -0.424 & -0.058 \\
\hline Weight of plant dries in hectare & 0.325 & -0.820 & -0.403 & -0.068 \\
\hline Variance & 3.8757 & 2.2573 & 1.9047 & 1.3452 \\
\hline \% var & 0.298 & 0.174 & 0.147 & 0.103 \\
\hline
\end{tabular}

tion covered 30 percent of the total variance. The second factor covered fresh yield of a plant by 17 percent of total variance and we can make the name of the second factor to biological factor. The third factor of main factor analysis included traits related to the vegetative growth stage that was covered by 15 percent of total variance. In this study, we can coin the term, the third factor to vegetative growth factor (Table 6). Cluster figure showed us that traits for this study divided into 3 sections. The first group was traits related to vegetative growth including stem diameter, to the weight of fresh plant and number of the nodes. Second group traits were related to seeds that included the 


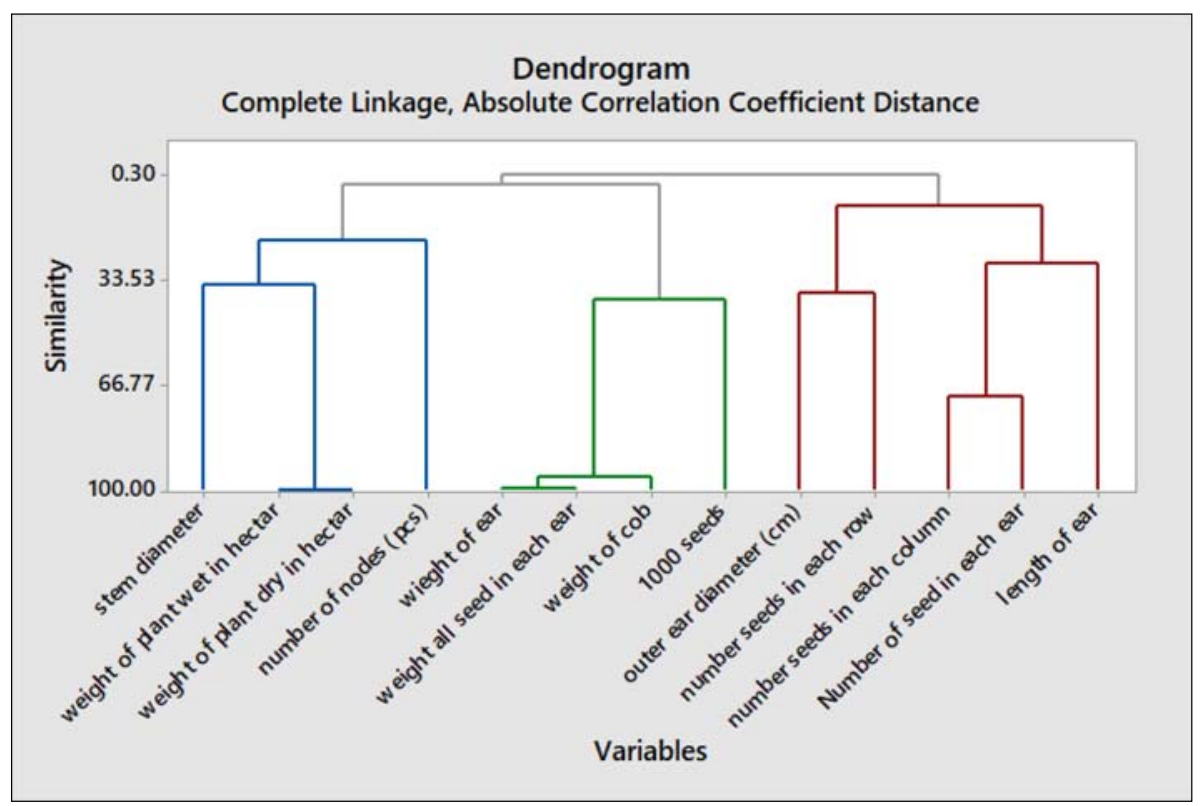

Fig. 1. Cluster and classification of the traits

weight of cob ear, the weight of seeds in an ear, the weight of one thousand seeds that we can name grain yield group. In the final analysis, third group traits were related to ear including a number of seeds in row and column, the number of seeds in the ear and length of an ear (Fig. 1).

Among the authors, Hejazi showed that traits of seed rows per ear and ear diameter and ear length explained $47.4 \%$ of the variation coefficients high positive in the first factor. Twenty-two percent of the variation explained in the second factor by grain yield and number of grains per ear. The third factor (cob weight) was $14.8 \%$ of the variation of the plant height, ear height and plant height (Hejazi et al., 2013).

\section{Effect of traits in fertilizer's levels by GGE biplot in H410 Hybrid}

\section{Determination of the ideal traits of different levels of fertilizer using the GGE biplot graphical method}

The graph result shows the ideal traits. Ideal traits have the highest recognition and representation abilities between other traits. Based on this, the ear weight and grain weight per ear were recognized as an ideal trait due to its proximity to the centre of the axis. Finally, as seen in the plot, the outer diam- 


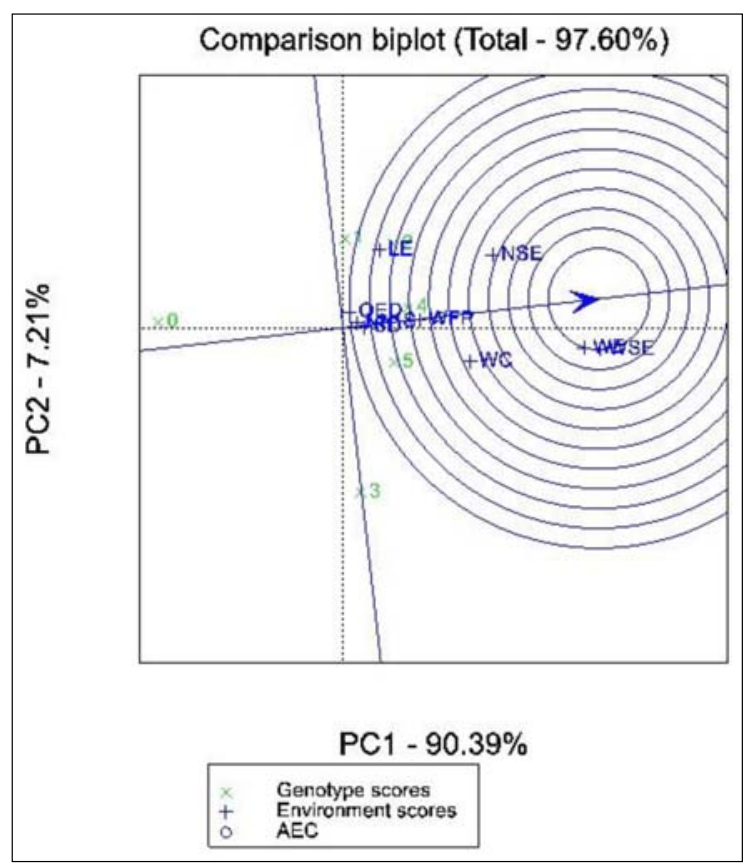

Fig. 2. Ranking of fertilizer levels with traits in H410 hybrid (stem diameter (SD), outer ear diameter (OD), number of nodes (NN), weight of ear(WE), weight of cob (WC), number seeds in each row (NSR), number seeds in each column (NSC), length of ear (LE), weight all seed in each ear (WSE), Number of seed in each ear (NSE), weight of fresh plant in hectare (WFP) one thousand seeds (1S).0-5 level of the NPK)

eter of the ear was introduced as the weakest trait due to having the greatest distance from the centre of the dual axis. It should be noted that the ideal trait is an appropriate representative for the study of the effects of fertilizer levels (although this does not reject the results of other traits). In fact, the ideal trait represents the most ideal response pattern for fertilizer levels (Fig. 2).

\section{Determination of the ideal fertilizer level for the studied traits using the GGE biplot graphical method}

One of the important applications of biplots is to identify the best fertilizer levels based on a various index or measured traits. The graph shows the number of fertilizer's levels based on the ideal fertilizer level. The ideal fertilizer is a level of fertilizer that is oriented towards the positive end of the middle axis of the various levels of fertilizer and its perpendicular distance from this line is reached minimum. To compare the different levels of fertilizer with the ideal level of the central axis this level is drawn. Other levels of fertility are arranged based on similarity and proximity to the ideal level 


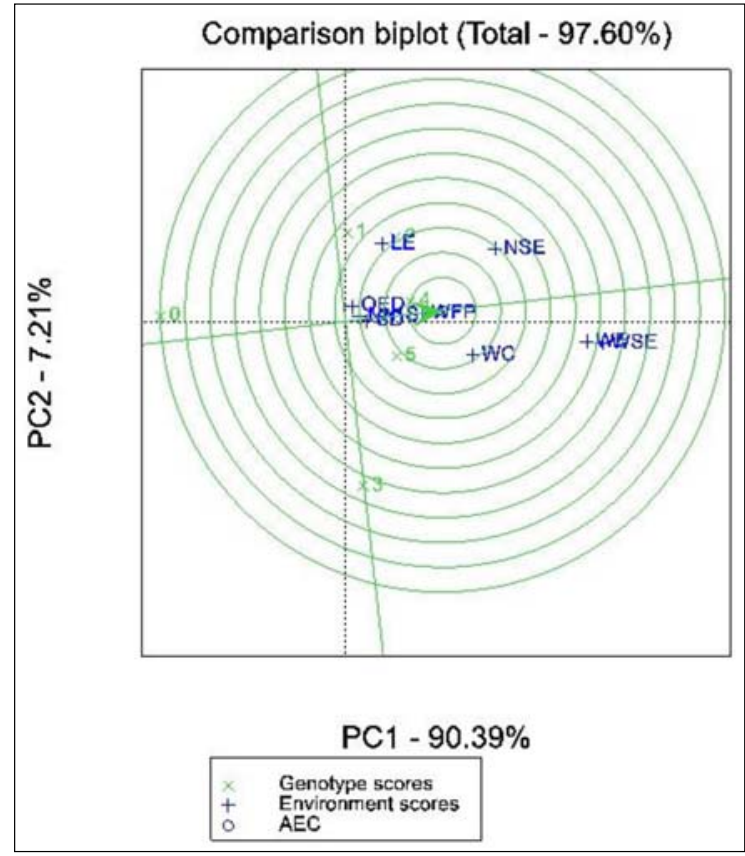

Fig. 3. Ranking of fertilizer levels with traits in $\mathrm{H} 410$ hybrid (stem diameter (SD), outer ear diameter (OD), number of nodes (NN), weight of ear(WE), weight of cob (WC), number seeds in each row (NSR), number seeds in each column (NSC), length of ear (LE), weight all seed in each ear (WSE), Number of seed in each ear (NSE), weight of fresh plant in hectare (WFP) one thousand seeds (1S).0-5 level of the NPK)

and it is easy to know the level of fertilizer or levels. On this basis, the ideal levels are level fourth and the desired levels are then fifth, second, first, third and zeroth. Levels fourth and fifth are the most desirable levels for the fresh weight of the plant (Fig. 3).

\section{Effect of traits in fertilizer's levels by GGE biplot in H340 Hybrid}

\section{Determination of the ideal traits of different levels of fertilizer using the GGE biplot graphical method}

The graph shows the ideal traits. Ideal traits actually have the highest recognition and representation abilities between other traits. Based on this, the weight of ear and the weight grain per ear were recognized as an ideal trait due to its proximity to the centre of the axis. Ultimately, as seen in this plot, 


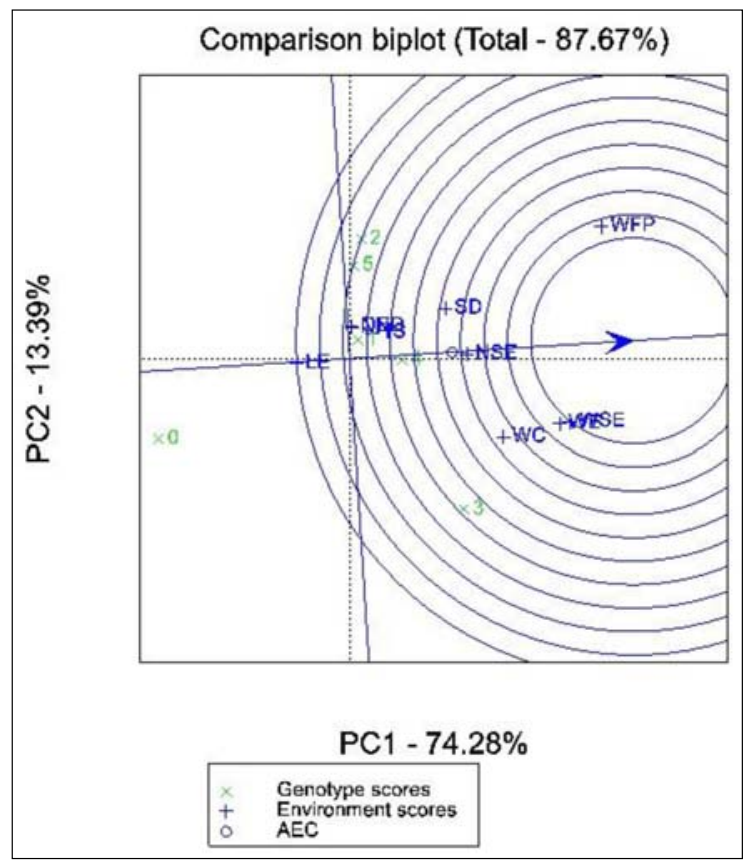

Fig. 4. Ranking of fertilizer levels with traits in 340 hybrid (stem diameter (SD), outer ear diameter (OD), number of nodes (NN), weight of ear(WE), weight of cob (WC), number seeds in each row (NSR), number seeds in each column (NSC), length of ear (LE), weight all seed in each ear (WSE), Number of seed in each ear (NSE), weight of fresh plant in hectare (WFP) one thousand seeds (1S).0-5 level of the NPK)

ear altitude was introduced as the weakest attribute due to having the greatest distance from the centre of the axis. It should be noted that the ideal trait is an appropriate representative for the study of the effects of fertilizer levels (although this does not reject the results of other traits). In fact, the ideal trait represents the most ideal response pattern for fertilizer levels (Fig. 4).

\section{Determination of the ideal fertilizer level for the studied traits using the GGE biplot graphical method}

One of the important applications of biplots is to identify the best fertilizer levels based on a various index or measured traits. The graph shows the number of fertilizer levels based on the ideal fertilizer level. The ideal fertilizer is a level of fertilizer that is oriented towards the positive end of the middle axis of the various levels of fertilizer and its perpendicular distance from this line is minimal. To compare the different levels of fertilizer with an ideal lev$\mathrm{el}$, the centre line of the coils is drawn to the centre of this level of fertilizer. Other levels of fertility are arranged based on similarity and proximity to the 


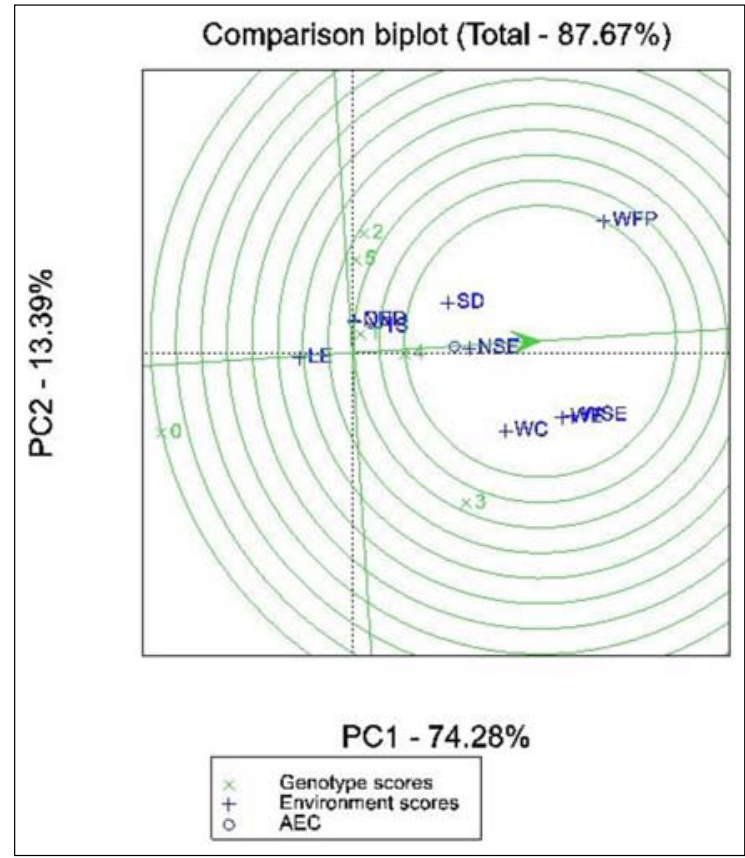

Fig. 5. Ranking of fertilizer levels with traits in 340 hybrid (stem diameter (SD), outer ear diameter (OD), number of nodes (NN), weight of ear(WE), weight of cob (WC), number seeds in each row (NSR), number seeds in each column (NSC), length of ear (LE), weight all seed in each ear (WSE), Number of seed in each ear (NSE), weight of fresh plant in hectare (WFP) one thousand seeds (1S).0-5 level of the NPK)

ideal level and it is easy to know the level of fertilizer or levels of fertilizer. Based on this, the ideal level is the fourth level and the desired levels are then third, second, first, fifth and zeroth levels. Fourth and third levels are the most desirable levels of fertilizer in terms of yield traits (Fig. 5).

\section{Conclusion}

A few ecological and biological factors influence the number of nutrients used in fertilizers (Fageria and Baligar, 2005; Cui et al., 2006). The researchers' results about the different nutritious utilization and fertilizers of maize hybrids show that yield in the nitrogen opt + phosphorus and potassium treatment have highest yield in this treatment. There are four different classifications about valuable hybrids that these were increasing yield more than the control treatment. (Pepo, 2006). In this study, the weight of seeds in ear and weight of ear were important traits for yield in H410 hybrid. Also, the fourth of the fertilizer level was the best level of fertilizer for yield in this hybrid. There is the highest relation in yield between the fourth level of fertilizer with weight 
of fresh plant, fifth level of fertilizer with weight of the one thousand seeds and first and second level of fertilizer with length of the ear in H410. Weight of fresh plant and weight of seeds in ear had been highest in relation with yield in H340 hybrid. Fourth of fertilizer level had more relation with stem diameter for yield, third of fertilizer level with the weight of cob and first and second and fifth of fertilizer level with outer diameter too. Our study showed fourth of fertilizer level was the best level of fertilizer on H410 and H340 hybrid in Debrecen region. Research results in this paper can successfully contribute to the science of maize genotypes, to the exploration of their traits and to an application of fertilizers adapted to the given hybrid.

\section{Acknowledgements}

The research was financed by the Higher Education Institutional Excellence Programme of the Ministry of Human Capacities in Hungary, within the framework of the 4 . thematic programme of the University of Debrecen, and the projects "GINOP-2.2.1-15-2016-00001 - Developing a scale-independent complex precision consultancy system" and "EFOP-3.6.3VEKOP-16-2017-00008".

\section{References}

Akintoye, H. A., Kling, J. G., Lucas, E. O. (1999) N-use efficiency of single, double and synthetic maize lines grown at four $\mathrm{N}$ levels in three ecological zones of West Africa. Field Crops Res. 60: 189-199.

Balko, L. G., Russell, W. A. (1980) Effects of rates of nitrogen fertilizer on maize inbred lines and hybrid progeny. I: Prediction of yield responses. Maydica 25: 65-79.

Bencze, G., Futó, Z. (2017) Effect of nutriment elements (NPK) to the crop of maize (Zea mays L.) in the year of 2016-2017. Research Journal of Agricultural Science 49(4): 46-53.

Cui, Z. L., Chen, X. P., Li, J. L., Xu, J. F., Shi, L. W., Zhang, F. S. (2006) Effect of N fertilization on grain yield of winter wheat and apparent $\mathrm{N}$ losses. Pedosphere 16: 806-812.

Devkota, M., Martius, C., Lamers, J. P. A., Sayre, K. D., Devkota, K. P., Gupta, R. K., Egamberdiev, O., Vlek, P. L. G. (2013) Combining permanent beds and residue retention with nitrogen fertilization improves crop yields and water productivity in irrigated arid lands under cotton, wheat and maize. Field Crop Res. 149: 105-114.

Duan, Y., Xu, M., Gao, S., Yang, X., Huang, S., Liu, H., Wang, B. (2014) Nitrogen use efficiency in a wheat-corn cropping system from 15 years of manure and fertilizer applications. Field Crops Res. 157: 47-56.

FAO (2009). How to Feed the World in 2050. Executive Summary, Food and Agriculture Organization of the United Nations.

Fageria, N. K., Baligar, V. C. (2005) Enhancing nitrogen use efficiency in crop plants. Advances in Agron. 88: 97-185.

Heisey, P., Norton, G. W. (2007) Fertilizer and other chemicals. In: Evenson, R. and Pingali, P. (eds). Handbook of Agricultural Economics, Vol. 3, p. 2747-2783. Elsevier BV, Amsterdam 
Hejazi, P., Mousavi, S. M. N., Mostafavi, K., Ghomshei, M. S., Hejazi, S., Navid Mousavi, S. M. (2013) Study on hybrids maize response for drought tolerance index. Advances in Environmental Biology 7(2): 333-338.

Li, Q. K., Zhu, Z. L., Yu, T. R. (1998) Fertilizer Questions in Sustainable Development of Agriculture in China. Jiangxi Science and Technology Press, Jiangxi, China, pp. 3-5.

Li, X. X., Hu, C. S., Delgado, J. A., Zhang, Y. M., Ouyang, Z. Y. (2007) Increased nitrogen use efficiencies as a key mitigation alternative to reduce nitrate leaching in North China Plain. Agric. Water Manage. 89: 137-147.

Ladha, J. K., Pathak, H., Krupnik, T. J., Six, J., van Kessel, C. (2005) Efficiency of fertilizer nitrogen in cereal production: retrospects and prospects. Adv. Agron. 87: 85-156.

Liu, X. J., Ju, X. T., Zhang, F. S., Pan, J. R., Christie, P. (2003) Nitrogen dynamics and budgets in a winter wheat-maize cropping system in the North China Plain. Field Crops Res. 83: 111-124.

Lü, P., Zhang, J. W., Liu, W., Yang, J. S., Su, K., Liu, P., Dong, S. T., Li, D. H. (2011) Effects of nitrogen application on yield and nitrogen use efficiency of summer maize under super-high yield conditions. Plant Nutr. Fertil. Sci. 17: 852-860.

Muruli, B. I., Paulsen, G. M. (1981) Improvement of nitrogen-use efficiency and its relationship to other traits in maize. Maydica 26: 63-73.

Nagy, J. (2006) Maize Production. Akadémiai Kiadó, Budapest

Pepó, P., Vad, A., Berényi, S. (2006) Effect of some agrotechnical elements on the yield of maize on chernozem soil. Cereal Res. Commun. 34: 621-624.

Pepó, P., Vad, A., Berényi, S. (2008) Effects of irrigation on yields of maize (Zea mays L.) in different crop rotation. Cereal Res. Commun. 36: 735-738.

Pepó, P., Karancsi, L.G. (2014) New results of nutrient utilization and response of maize (Zea mays L.) hybrids.journal of agricultural and environmental sciences vol. 1, no. 2.

Raun, W. R., Solie, J. B., Johnson, G. V., Stone, M. L., Mullen, R. W., Freeman, K. W., Thomason, W. E., Lukina, V. (2002) Improving nitrogen use efficiency in cereal grain production with optical sensing and variable rate application. Agron. J. 94: 815-820.

Schröder, J. J., Smith, A. L., Cordell, D., Rosemarin, A. (2011) Improved phosphorus use efficiency in agriculture, a key requirement for its sustainable use. Chemosphere 84: 822-831.

Smil, V. (2011a) Harvesting the Biosphere: How Much We Have Taken from Nature. Cambridge, MA, The MIT Press. In press.

Tilman, D., Balzer, C., Hill, J., Befort, B. L. (2011) Global food demand and the sustainable intensification of agriculture. PNAS Early Edition. Available online: www.pnas.org/ cgi/doi/10.1073/pnas.1116437108.

Van Groenigen, J. W., Velthof, G. L., Oenema, O., Van Groenigen, K. J., Van Kessel, C. (2010) Towards an agronomic assessment of $\mathrm{N}_{2} \mathrm{O}$ emissions: a case study for arable crops. Eur. J. Soil Sci. 61: 903-913.

Zhu, Z. L., Wen, Q. X. (1992) Soil Nitrogen in China. Jiangsu Science and Technology Press. Jiangsu, China. pp. 228-231.

Open Access statement. This is an open-access article distributed under the terms of the Creative Commons Attribution 4.0 International License (https:/ / creativecommons.org/ licenses/by/4.0/), which permits unrestricted use, distribution, and reproduction in any medium, provided the original author and source are credited, a link to the CC License is provided, and changes - if any - are indicated. (SID_1) 